\title{
Acute effects of cocaine, morphine and their combination on bioenergetic function and susceptibility to oxidative stress of rat liver mitochondria
}

\author{
Teresa Cunha-Oliveira ${ }^{a, *, 1}$, Lisbeth Silva ${ }^{\mathrm{a}, 1}$, Ana Maria Silva ${ }^{\mathrm{a}}$, António J. Moreno ${ }^{\mathrm{c}}$, \\ Catarina R. Oliveira ${ }^{\mathrm{a}, \mathrm{b}}$, Maria S. Santos ${ }^{\mathrm{a}, \mathrm{c}}$ \\ a CNC - Center for Neuroscience and Cell Biology, University of Coimbra, Largo Marquês de Pombal, 3004-517 Coimbra, Portugal \\ ${ }^{\mathrm{b}}$ Faculty of Medicine, University of Coimbra, 3004-504 Coimbra, Portugal \\ c Life Sciences Department, Faculty of Sciences and Technology, University of Coimbra, Apartado 3046, 3001-401 Coimbra, Portugal
}

\section{A R T I C L E I N F O}

\section{Article history:}

Received 2 February 2013

Accepted 29 April 2013

\section{Keywords:}

Cocaine

Morphine

Speedball

Mitochondria

Liver

Oxidative stress

Bioenergetics

\begin{abstract}
A B S T R A C T
Aims: Cocaine and heroin are frequently co-abused in a combination known as speedball. Despite the relevance of the liver in the metabolism and detoxification of these drugs, little is known about the impact of speedball on liver function.

Main methods: In this work, we evaluated the effects of cocaine, morphine and morphine + cocaine (Mor + Coc) combination (1:1) in isolated rat liver mitochondria, upon glutamate/malate or succinate energization, on bioenergetics and oxidative stress-related parameters by using $\mathrm{Clark}_{2}, \mathrm{Ca}^{2+}, \mathrm{TPP}^{+}$and $\mathrm{pH}$ electrodes and by measuring thiobarbituric acid reactive substances (TBARS) and $\mathrm{H}_{2} \mathrm{O}_{2}$ production.

Key findings: Cocaine and Mor + Coc at the higher concentrations ( $1 \mathrm{mM})$ similarly increased $\mathrm{O}_{2}$ consumption at state 2 , state 4 and state oligomycin. In these conditions, maximum respiration was decreased only upon glutamate/malate energization, suggesting an involvement of complex I. Morphine ( $1 \mathrm{mM}$ ) only increased state 2 respiration. Cocaine and Mor + Coc induced a similar decrease in maximum mitochondrial membrane potential and in ADP-induced depolarization, whereas morphine had no effect. The drugs and their combination similarly decreased mitochondrial ATPase activity and had no effect on $\mathrm{Ca}^{2+}$-induced permeability transition. Morphine and Mor + Coc prevented lipid peroxidation, since in these conditions there was a decrease in $\mathrm{O}_{2}$ consumption and in TBARS upon ADP/Fe ${ }^{2+}$ stimulus, and a decrease in $\mathrm{H}_{2} \mathrm{O}_{2}$ formation, suggesting an antioxidant effect. Interestingly, heroin did not share morphine antioxidant properties.

Significance: Our results show that the sequential direct exposure of liver mitochondria to morphine and cocaine does not alter the effects observed in the presence of each drug alone.
\end{abstract}

(c) 2013 Elsevier Inc. All rights reserved.

\section{Introduction}

Cocaine and heroin are two of the most problematic illicit drugs of abuse (Nutt et al., 2007). Cocaine is the second most used illicit drug in Europe (after cannabis) and heroin use accounts for the greatest share of morbidity and mortality related to drug use in the European Union (European Monitoring Center for Drugs and Drug Addiction, 2012). Polydrug abuse is a widespread phenomenon among drug addicts, with serious health consequences (European Monitoring Center for Drugs and Drug Addiction, 2009). Co-consumption of cocaine and heroin is very common since these drugs have complementary effects (stimulant and sedative, respectively), thereby reducing the secondary effects of one another, and may occur either sequentially or simultaneously (Leri et al., 2003). In mixtures of cocaine and heroin, chemical interactions between cocaine and morphine (heroin metabolite) may

\footnotetext{
* Corresponding author. Tel.: + 351239820 190; fax: + 351239822776

E-mail addresses: mteroliv@cnc.cj.uc.pt, teresa.oliveira@gmail.com (T. Cunha-Oliveira).

1 These authors contributed equally to this work.
}

occur, resulting in the formation of adducts between the two molecules at a 1:1 proportion (Garrido et al., 2007), which may modify the molecular effects of speedball.

We have previously shown that acute exposure to both cocaine (Cunha-Oliveira et al., 2006a) and heroin (Cunha-Oliveira et al., 2007) induces neurotoxicity in rat cortical neurons, in a process involving mitochondrial dysfunction and cell death by apoptosis. We have also shown that cocaine-heroin combinations induced mitochondrial depolarization, ATP loss and cytochrome c release in rat cortical neurons (Cunha-Oliveira et al., 2010). Thus, the cytotoxicity of cocaine and/or heroin seems to involve mitochondrial dysfunction, pointing out the mitochondria as a main intracellular target of the cytotoxicity of these drugs.

Heroin has a very short half-life and is rapidly metabolized into 6-acetylmorphine and morphine, which mediate many of heroin's effects in the organism (Cunha-Oliveira et al., 2008). Cocaine and morphine, as most drugs, are metabolized in the liver, with mitochondria playing a central role, and this organ is highly affected by each of these drugs (Bekheet, 2010; Van Thiel and Perper, 1992). Since little is 
known about speedball hepatotoxicity, in the present study we compared the effects of 1:1 morphine + cocaine (Mor + Coc) sequential combination in mitochondria isolated from rat liver with the effects of cocaine and morphine alone, focusing on the bioenergetic function and susceptibility to oxidative stress.

\section{Materials and methods}

\section{Chemicals}

Cocaine hydrochloride and morphine sulfate salt pentahydrate were obtained from Sigma-Aldrich Co. (St Louis, MO, USA), upon authorization by INFARMED, Portugal (National Authority of Medicines and Health Products). All of the other chemicals were of the highest grade of purity commercially available.

\section{Animals}

Male Wistar-han adolescent rats (9-12 weeks old) were maintained in our animal house, under controlled light (12 h day/night cycle), temperature and humidity, with ad libitum access to food and water. Procedures were approved by the Institutional Animal Care and Use Committee.

\section{Isolation of liver mitochondria}

The animals were sacrificed by cervical displacement and liver mitochondria were isolated by a conventional method (Gazzotti et al., 1979), with slight modifications. Livers were homogenized immediately in ice-cold homogenization medium containing $250 \mathrm{mM}$ sucrose, $10 \mathrm{mM}$ HEPES, $0.5 \mathrm{mM}$ EGTA, and $0.1 \%$ defatted bovine serum albumin ( $\mathrm{pH}$ 7.4). The homogenate was centrifuged for $10 \mathrm{~min}$ at $900 \times \mathrm{g}$ and mitochondria were recovered from supernatant, and pelleted at $10000 \times g$ for $10 \mathrm{~min}$. The mitochondrial pellet was washed twice and suspended in the washing medium (250 mM sucrose, $10 \mathrm{mM}$ HEPES, $\mathrm{pH}$ 7.4). Protein content was determined by the biuret method (Gornall et al., 1949), using bovine serum albumin as a standard.

\section{Mitochondrial respiration}

Mitochondrial oxygen consumption was monitored polarographically at $30{ }^{\circ} \mathrm{C}$ with a Clark-type oxygen electrode (Yellow Spring Instrument, Model YSI5331) (Estabrook, 1967) connected to a Kipp and Zonen recorder in a thermostatic water-jacketed chamber with magnetic stirring. Liver mitochondria ( $1 \mathrm{mg}$ ) were incubated, for $1 \mathrm{~min}$, in $1 \mathrm{ml}$ of the

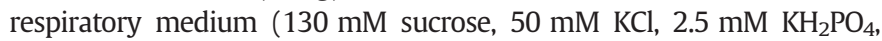
$5 \mathrm{mM}$ HEPES and $2 \mathrm{mM} \mathrm{MgCl}_{2} \mathrm{pH} 7.4$ ) in the absence or presence of the drugs, alone or combined at $0.2-1 \mathrm{mM}$, and energized with $10 \mathrm{mM}$ glutamate/ $5 \mathrm{mM}$ malate or $5 \mathrm{mM}$ succinate. When succinate was used as respiratory substrate, the medium was supplemented with $2 \mu \mathrm{M}$ rotenone. State 3 was initiated with ADP $(125 \mathrm{nmol} / \mathrm{mg}$ protein) and state oligomycin with ADP $(125 \mathrm{nmol})$ and oligomycin $(1 \mu \mathrm{g} / \mathrm{ml})$ (Fig. 1A). Respiration rates were calculated considering a saturation oxygen concentration of $240 \mathrm{nmol} \mathrm{O}_{2} / \mathrm{ml}$ at $30{ }^{\circ} \mathrm{C}$. States 3 and 4 and respiratory control ratio $(\mathrm{RCR}=$ state $3 /$ state 4$)$ were calculated according to Chance and Williams (1956). Uncoupled respiration was initiated by the addition of $1 \mu \mathrm{M}$ FCCP to the mitochondria respiring in state 4 respiration.

\section{Membrane potential $(\Delta \Psi)$ measurements}

The mitochondrial transmembrane potential $(\Delta \Psi)$ was monitored by evaluating transmembrane distribution of the lipophilic cation $\mathrm{TPP}^{+}$(tetraphenylphosphonium) with a $\mathrm{TPP}^{+}$-selective electrode prepared according to Kamo et al. (1979) using $\mathrm{Ag} / \mathrm{AgCl}_{2}$-saturated electrode as reference. $\mathrm{TPP}^{+}$uptake was assessed from the decreased
$\mathrm{TPP}^{+}$concentration in the medium sensed by the electrode. The difference between the potential of the selective electrode and the reference electrode was measured with an electrometer and recorder continuously in a Kipp and Zonen recorder. The voltage response of the $\mathrm{TPP}^{+}$electrode to $\log \left[\mathrm{TPP}^{+}\right]$was linear with a slope of $59 \pm 1$, in a good agreement with Nernst equation.

To monitor $\Delta \Psi$ associated to mitochondrial respiration, the mitochondria $(1 \mathrm{mg} / \mathrm{ml})$ were incubated in the standard respiratory medium supplemented with $3 \mu \mathrm{M} \mathrm{TPP}^{+}$(and $2 \mu \mathrm{M}$ rotenone if succinate was the respiratory substrate), at $30{ }^{\circ} \mathrm{C}$, in the absence or presence of different concentrations of the drugs alone or combined, for $1 \mathrm{~min}$, prior to the addition of $10 \mathrm{mM}$ glutamate $/ 5 \mathrm{mM}$ malate or $5 \mathrm{mM}$ succinate to start the reaction. After steady-state distribution of $\mathrm{TPP}^{+}$had been reached ADP (125 nmol/mg protein) was added and $\Delta \Psi$ fluctuations were recorded.

\section{Mitochondrial ATPase activity}

The activity of mitochondrial ATPase was evaluated through detection of $\mathrm{pH}$ changes occurring during ATP hydrolysis, as described previously (Madeira et al., 1974), with some modifications. The mitochondria (1.5 mg of protein) were incubated in $1.5 \mathrm{ml}$ of reaction media (130 mM sucrose, $50 \mathrm{mM} \mathrm{KCl,} 2.5 \mathrm{mM} \mathrm{MgCl}_{2}, 0.5 \mathrm{mM}$ HEPES, $\mathrm{pH}$ 7.2) supplemented with $3 \mu \mathrm{M}$ rotenone. The drugs were incubated alone or combined at $0.4 \mathrm{mM}$ and $1 \mathrm{mM}$, for $1 \mathrm{~min}$. The reaction was initiated by the addition of $1 \mathrm{mM}$ ATP $/ \mathrm{Mg}^{2+}$. Oligomycin was used as a selective inhibitor of ATPase ( $\mathrm{F}_{\mathrm{O}}$ unit) and completely abolished $\mathrm{pH}$ alterations. Known concentrations of $\mathrm{NaOH}$ were used to calibrate the system.

\section{$\mathrm{Ca}^{2+}$-induced mitochondrial permeability transition (MPT) pore}

The accumulation and release of $\mathrm{Ca}^{2+}$ by the mitochondria is related with MPT pore opening. Monitoring of $\mathrm{Ca}^{2+}$ accumulation by the mitochondria, using an electrode for $\mathrm{Ca}^{2+}$ or for $\mathrm{TPP}^{+}$can give information about the effect of drugs on MPT.

In order to detect $\mathrm{Ca}^{2+}$-induced MPT we used a $\mathrm{TPP}^{+}$electrode, according to procedures previously described, with some modifications (Fernandes et al., 2008). To monitor $\Delta \Psi$ associated to MPT, the liver mitochondria ( $1 \mathrm{mg}$ ) were incubated, for $1 \mathrm{~min}$, in $1 \mathrm{ml}$ of reaction medium (200 mM sucrose, $1 \mathrm{mM} \mathrm{KH}_{2} \mathrm{PO}_{4}, 10 \mu \mathrm{M}$ EGTA, $10 \mathrm{mM}$ HEPES ( $\mathrm{pH} 7.4$ adjusted with Tris) supplemented with $2 \mu \mathrm{M}$ rotenone, in the absence and presence of the drugs ( $1 \mathrm{mM}$ ), isolated or in combination. The reactions were started by the addition of $5 \mathrm{mM}$ succinate followed by the addition of pulses of $\mathrm{Ca}^{2+}\left(40 \mathrm{nmol} \mathrm{Ca}^{2+} / \mathrm{mg}\right.$ protein $)$. Control assays with $\mathrm{Ca}^{2+}$, in the absence or presence of the MPT inhibitor cyclosporin A (CsA, $0.8 \mu \mathrm{M})$, were also performed.

Mitochondrial $\mathrm{Ca}^{2+}$ fluxes were also evaluated by monitoring the changes in $\mathrm{Ca}^{2+}$ concentration in the reaction medium using a $\mathrm{Ca}^{2+}$-sensitive electrode, according to procedures previously described (Custodio et al., 1998; Madeira, 1975). The reactions were performed in an open vessel with magnetic stirring in $1 \mathrm{ml}$ of the reaction medium supplemented with $200 \mathrm{nmol} \mathrm{CaCl}_{2} / \mathrm{mg}$ protein, and started by the addition of $5 \mathrm{mM}$ succinate to mitochondrial suspensions (1 mg) previously incubated in the absence or presence of the drugs or their 1:1 combination ( $1 \mathrm{mM})$. Control assays, in the absence and presence of $0.8 \mu \mathrm{M}$ CsA, were also performed.

\section{Evaluation of oxidative stress}

The extent of lipid peroxidation was evaluated by oxygen consumption monitored polarographically at $30{ }^{\circ} \mathrm{C}$ using a Clark-type oxygen electrode placed in a glass chamber equipped with magnetic stirring (Santos et al., 2001). The mitochondria (1 mg) were pre-incubated with the drugs, alone or combined $1: 1(1 \mathrm{mM})$, for $2 \mathrm{~min}$ in $1 \mathrm{ml}$ of reaction medium containing $175 \mathrm{mM} \mathrm{KCl}, 10 \mathrm{mM}$ Tris- $\mathrm{HCl}$ (pH 7.4) 
A

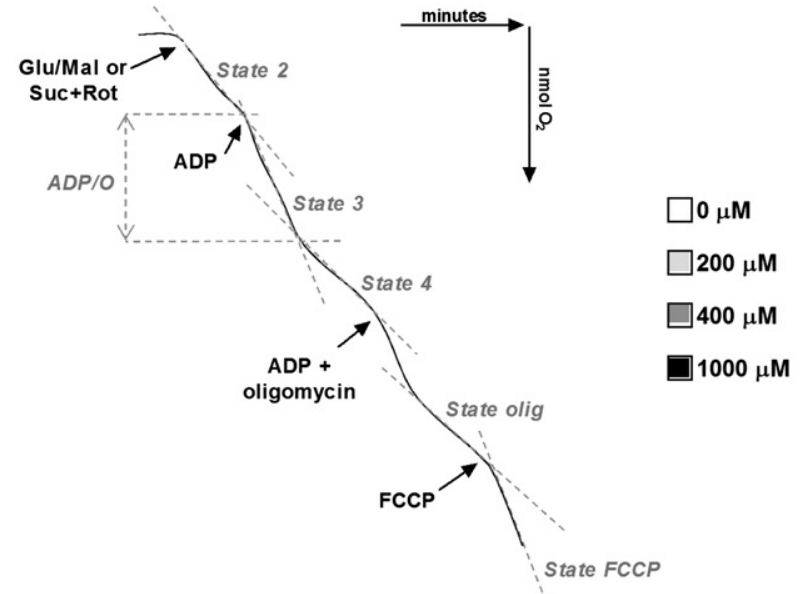

B
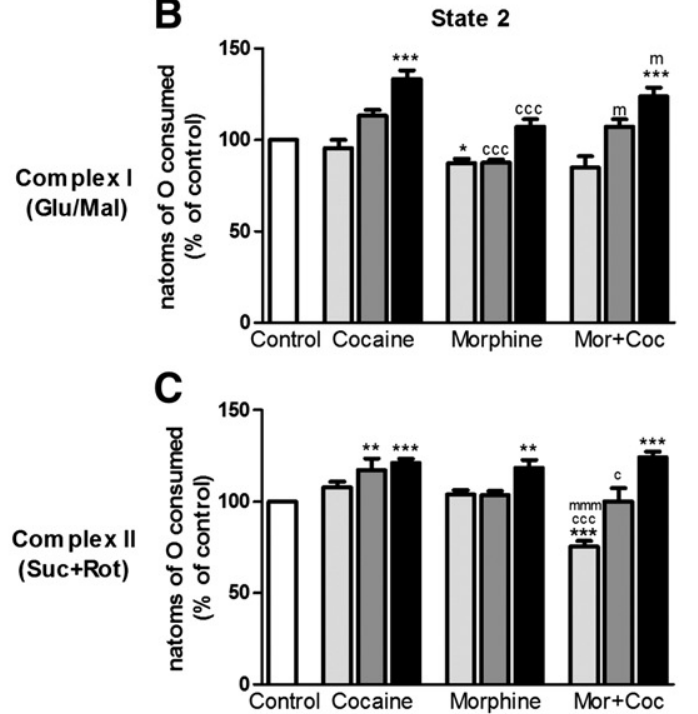
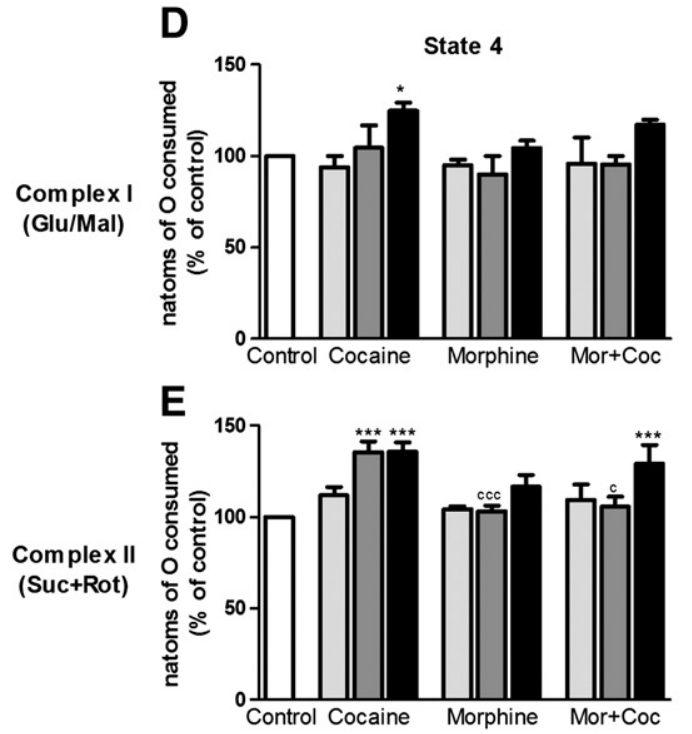

$\mathbf{F}$

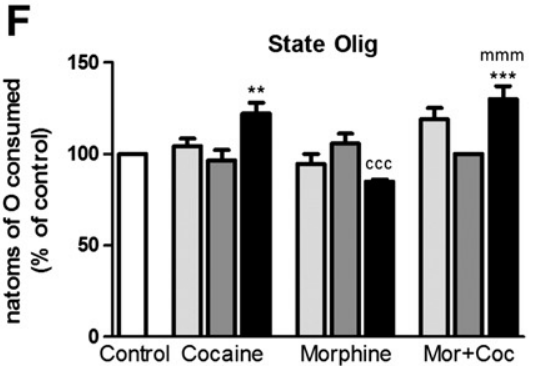

H State FCCP

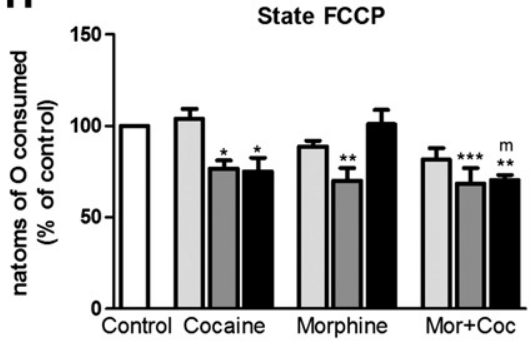

G
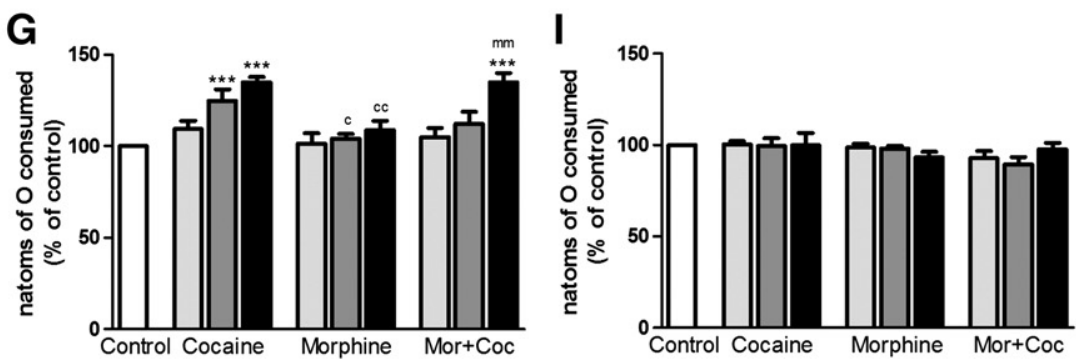

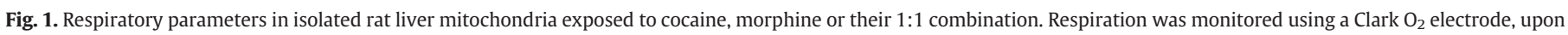

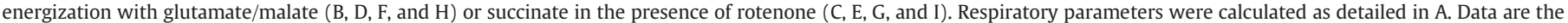

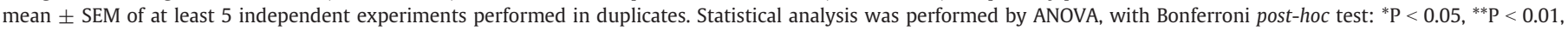

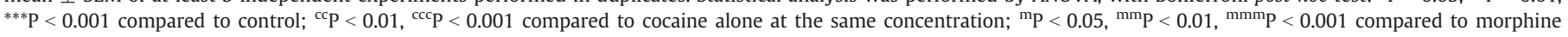
alone at the same concentration.

and $3 \mu \mathrm{M}$ rotenone to avoid mitochondrial respiration induced by endogenous respiratory substrates. Membrane lipid peroxidation was started by the addition of $1 \mathrm{mM} \mathrm{ADP} / 0.1 \mathrm{mM} \mathrm{Fe}^{2+}$, changes in oxygen tension were recorded and oxygen consumption was calculated assuming an oxygen concentration of $240 \mathrm{nmol} \mathrm{O} / 2 \mathrm{ml}$. Controls in the absence of $\mathrm{ADP} / \mathrm{Fe}^{2+}$ were performed.

In parallel, the extent of lipid peroxidation was also determined by measuring the formation of thiobarbituric acid reactive substances (TBARS), using the thiobarbituric acid assay, according to a modified procedure described elsewhere (Santos et al., 2001). Aliquots of mitochondrial suspensions $\left(0.5 \mathrm{mg}\right.$ ) removed after $10 \mathrm{~min}$ of $\mathrm{ADP} / \mathrm{Fe}^{2+}$ addition were mixed with $0.5 \mathrm{ml}$ of ice-cold $40 \%$ trichloroacetic acid. Then, $2 \mathrm{ml}$ of $0.67 \%$ of aqueous thiobarbituric acid containing $0.01 \%$ of 2,6 -di-tert-butyl-p-cresol was added. The mixtures were heated at $90{ }^{\circ} \mathrm{C}$, cooled and centrifuged at $850 \times \mathrm{g}$ for $10 \mathrm{~min}$. The lipid peroxidation was measured in the supernatant fractions at $530 \mathrm{~nm}$ and the amount of TBARS formed was calculated using a molar extinction coefficient of $1.56 \times 10^{5} \mathrm{M}^{-1} \mathrm{~cm}^{-1}$ and expressed as nmol TBARS/mg protein.

The rate of $\mathrm{H}_{2} \mathrm{O}_{2}$ production was measured fluorimetrically using a modification of the method described by Barja (2002). Briefly, mitochondrial protein $(0.125 \mathrm{mg})$ was incubated at $30{ }^{\circ} \mathrm{C}$ in $0.5 \mathrm{ml}$ of

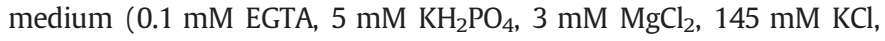
$30 \mathrm{mM}$ HEPES, pH 7.4) supplemented with $0.1 \mathrm{mM}$ homovanilic acid, and $6 \mathrm{U} / \mathrm{ml}$ horseradish peroxidase. A fluorescent dimer of homovanilic acid is formed upon reaction with $\mathrm{H}_{2} \mathrm{O}_{2}$, in the presence of horseradish peroxidase, allowing the assessment of $\mathrm{H}_{2} \mathrm{O}_{2}$ levels in the samples. The reactions were started by adding $10 \mathrm{mM}$ glutamate $/ 5 \mathrm{mM}$ malate or $5 \mathrm{mM}$ succinate and stopped 15 min later with $250 \mu \mathrm{l}$ of cold $0.1 \mathrm{mM}$ glycine- $\mathrm{NaOH}$ ( $\mathrm{pH} 12$ ) containing $25 \mathrm{mM}$ EDTA. Experiments were performed in the absence or presence of the drugs (cocaine, heroin, morphine, and Mor + Coc 1:1) $(1 \mathrm{mM}), 1 \mu \mathrm{M}$ rotenone, $10 \mu \mathrm{M}$ antimycin $\mathrm{A}$, or catalase. In order to assess baseline $\mathrm{H}_{2} \mathrm{O}_{2}$ produced by the mitochondria, experiments were also performed in the absence of a substrate. 
The mitochondrial suspensions were centrifuged at $1075 \times \mathrm{g}$ for $2 \mathrm{~min}$. The fluorescence of supernatants was measured at $312 \mathrm{~nm}$ excitation and $420 \mathrm{~nm}$ emission wavelengths. The rate of $\mathrm{H}_{2} \mathrm{O}_{2}$ was calculated using a standard curve made with known concentrations of $\mathrm{H}_{2} \mathrm{O}_{2}$.

\section{Statistical analysis}

Data are expressed as means \pm S.E.M. and evaluated by one-way analyses of variance (ANOVA) followed by Bonferroni multiple comparison tests. Differences were considered to be statistically significant at $p$ value lower than 0.05 . All analyses were performed using GraphPad Prism 5.0 for Windows.

\section{Results}

Cocaine and Mor $+\operatorname{Coc}(1: 1)$ affect the respiratory chain

To understand the effects of speedball on liver mitochondrial function, we started by evaluating oxygen consumption in the presence of the drugs alone or their 1:1 combination, and analyzed several respiratory parameters (Fig. 1A).

The addition of cocaine $(0.2,0.4$ and $1 \mathrm{mM})$ to freshly isolated mitochondria produced no changes in oxygen consumption during ADP-stimulated state 3 respiration, or on RCR or ADP/O ratios (not shown). The higher concentration of cocaine significantly increased the oxygen consumption during state 2 (Fig. 1B, C), state 4 (Fig. 1D, E) and state oligomycin (Fig. 1F, G). State FCCP, corresponding to maximum respiration, decreased in the presence of higher concentrations of cocaine, but only when the substrate was glutamate/malate (Fig. 1H, I). The combination Mor $+\operatorname{Coc}(1: 1)$ presented similar effects in the respiratory chain compared to cocaine alone (Fig. 1B-I), whereas morphine alone also increased state 2 respiration (Fig. 1C) but did not affect most of the respiratory parameters (Fig. 1D-G, I).

\section{Cocaine and Mor $+\operatorname{Coc}(1: 1)$ induced mitochondrial depolarization}

Maximum potential is achieved upon energization of the mitochondria with glutamate/malate or succinate, through complex I or complex II, respectively. In the presence of the higher concentration ( $1 \mathrm{mM})$ of cocaine or the combination Mor $+\operatorname{Coc}(1: 1)$, the maximum potential was significantly decreased (Fig. 2A, B), compared to controls. After the addition of ADP, mitochondrial potential decreases due to the action of ATP synthase, which uses the energy from the proton motive force (generated by respiration) to phosphorylate the ADP. The highest concentrations tested of cocaine or the combination Mor $+\operatorname{Coc}(1: 1)$ induced a significant decrease in ADP-induced depolarization (Fig. 2C, D), whereas morphine did not affect any of these parameters (Fig. 2A-D).

Cocaine, morphine and their combination (1:1) affect mitochondrial ATPase activity

The mitochondrial ATP synthase can, in certain circumstances, function as ATPase, hydrolyzing cellular ATP. In the presence of cocaine, morphine and the combination Mor + Coc (1:1) (1 mM) the production of $\mathrm{H}^{+}$resulting from the hydrolysis of ATP decreased significantly, suggesting that the drugs, isolated or combined (1:1), induced a significant decrease in ATPase activity (Fig. 2E), which may be directly attributed to interference with the F1 component of the enzyme. The combination Mor + Coc presented a synergistic action, increasing the inhibitory effect of each drug on the ATPase subunit.

\section{The drugs alone or combined do not affect the $\mathrm{Ca}^{2+}$-induced MPT}

The effect of the drugs, isolated or combined, on the MPT was evaluated by measuring $\Delta \Psi$ drop, which is a typical phenomenon that follows the induction of MPT. After succinate-induced increase in $\Delta \Psi$, a subsequent pulse of calcium ( $40 \mathrm{nmol} \mathrm{Ca}^{2+}$ ) promoted, in all experimental conditions, a depolarization followed by rapid repolarization (Fig. 3A). Total mitochondrial depolarization occurred only after the addition of the second pulse of calcium ( $\left.40 \mathrm{nmol} \mathrm{Ca}^{2+}\right)$, except in the presence of $0.8 \mu \mathrm{M}$ CsA (a specific inhibitor of the MPT pore). As previously observed (see Fig. 2A-B), cocaine and the combination Mor $+\operatorname{Coc}(1: 1)(1 \mathrm{mM})$ induced a decrease in the maximum $\Delta \Psi$ upon succinate energization. However, the control mitochondria and the mitochondria incubated with cocaine, morphine and the combination Mor $+\operatorname{Coc}(1: 1)$ showed a similar behavior after the addition of the second pulse of $\mathrm{Ca}^{2+}$, suggesting that the opening of the MPT pore occurred in a similar way (Fig. 3A). Morphine alone did not affect $\mathrm{Ca}^{2+}$-induced MPT (Fig. 3A).

Another way of studying the $\mathrm{Ca}^{2+}$-induced MPT is by evaluating the $\mathrm{Ca}^{2+}$ accumulated by the mitochondria, using a $\mathrm{Ca}^{2+}$ electrode (Fig. 3B). The control mitochondria and the mitochondria incubated with morphine showed a similar behavior, accumulating calcium which was quickly released due to the opening of the MPT pore (Fig. 3B). In the presence of morphine and CsA all the $\mathrm{Ca}^{2+}$ was retained in the mitochondria, confirming the involvement of the MPT pore. The mitochondria incubated with cocaine and the combination Mor $+\mathrm{Coc}$ (1:1) (1 mM) accumulated less $\mathrm{Ca}^{2+}$ (Fig. 3B), consequently delaying MPT pore opening. This inability of the mitochondria to accumulate $\mathrm{Ca}^{2+}$ is likely related to the lowest potential reached in these conditions (Fig. 2A, B). Apparently, the combination Mor + Coc (1:1) seemed to promote the induction of MPT pore in a small fraction of the mitochondria (Fig. 3B).

\section{Morphine and Mor $+\operatorname{Coc}(1: 1)$ have an antioxidant effect}

Oxygen consumption and TBARS levels were used to determine the extension of lipid peroxidation induced by $\mathrm{ADP} / \mathrm{Fe}^{2+}$ (Fig. 4). Regarding oxygen consumption, the control mitochondria and the mitochondria incubated with cocaine $(1 \mathrm{mM})$ consumed oxygen at a very similar rate, upon exposure to $\mathrm{ADP} / \mathrm{Fe}^{2+}$ (Fig. $4 \mathrm{~A}$ ). In turn, in the mitochondria incubated with morphine and the combination Mor $+\operatorname{Coc}(1: 1)(1 \mathrm{mM})$ the time for initiation of peroxidation increased and there was a slight decrease in oxygen consumption (Fig. 4A). Accordingly, the levels of TBARS in the mitochondria incubated with morphine and the combination Mor + Coc (1:1) decreased significantly (Fig. 4B), suggesting an antioxidant effect of morphine. The control mitochondria and the mitochondria incubated with cocaine produced a similar amount of TBARS (Fig. 4B).

The production of $\mathrm{H}_{2} \mathrm{O}_{2}$ by the mitochondria gives an indication about the propensity of the mitochondria to originate and/or exacerbate oxidative stress. In the absence of inhibitors of mitochondrial respiratory chain activity, the levels of $\mathrm{H}_{2} \mathrm{O}_{2}$ generated by the mitochondria respiring upon addition of glutamate/malate or succinate were low. However, in the presence of rotenone (an inhibitor of complex I) or antimycin A (AA; an inhibitor of complex III) the levels of $\mathrm{H}_{2} \mathrm{O}_{2}$ increased significantly (Fig. 5), due to increased electron leak and superoxide production at the level of these complexes, and subsequent conversion into $\mathrm{H}_{2} \mathrm{O}_{2}$ by superoxide dismutases.

We analyzed the effect of the drugs $(1 \mathrm{mM})$ on the generation of $\mathrm{H}_{2} \mathrm{O}_{2}$ by the mitochondria respiring upon glutamate/malate or succinate addition, in the absence (basal) and in the presence of rotenone and AA. Morphine and the combination Mor + Coc (1:1) significantly decreased the generation of $\mathrm{H}_{2} \mathrm{O}_{2}$ by the mitochondria in the presence of $\mathrm{AA}$ or rotenone (Fig. 5A, B).

To determine whether the antioxidant capacity of morphine on the formation of $\mathrm{H}_{2} \mathrm{O}_{2}$ is specific to this molecule, we also tested the effect of heroin. Interestingly, the mitochondria energized with glutamate/malate and incubated with morphine showed a more pronounced decrease in $\mathrm{H}_{2} \mathrm{O}_{2}$ production than the mitochondria incubated with heroin (Fig. 5C). 

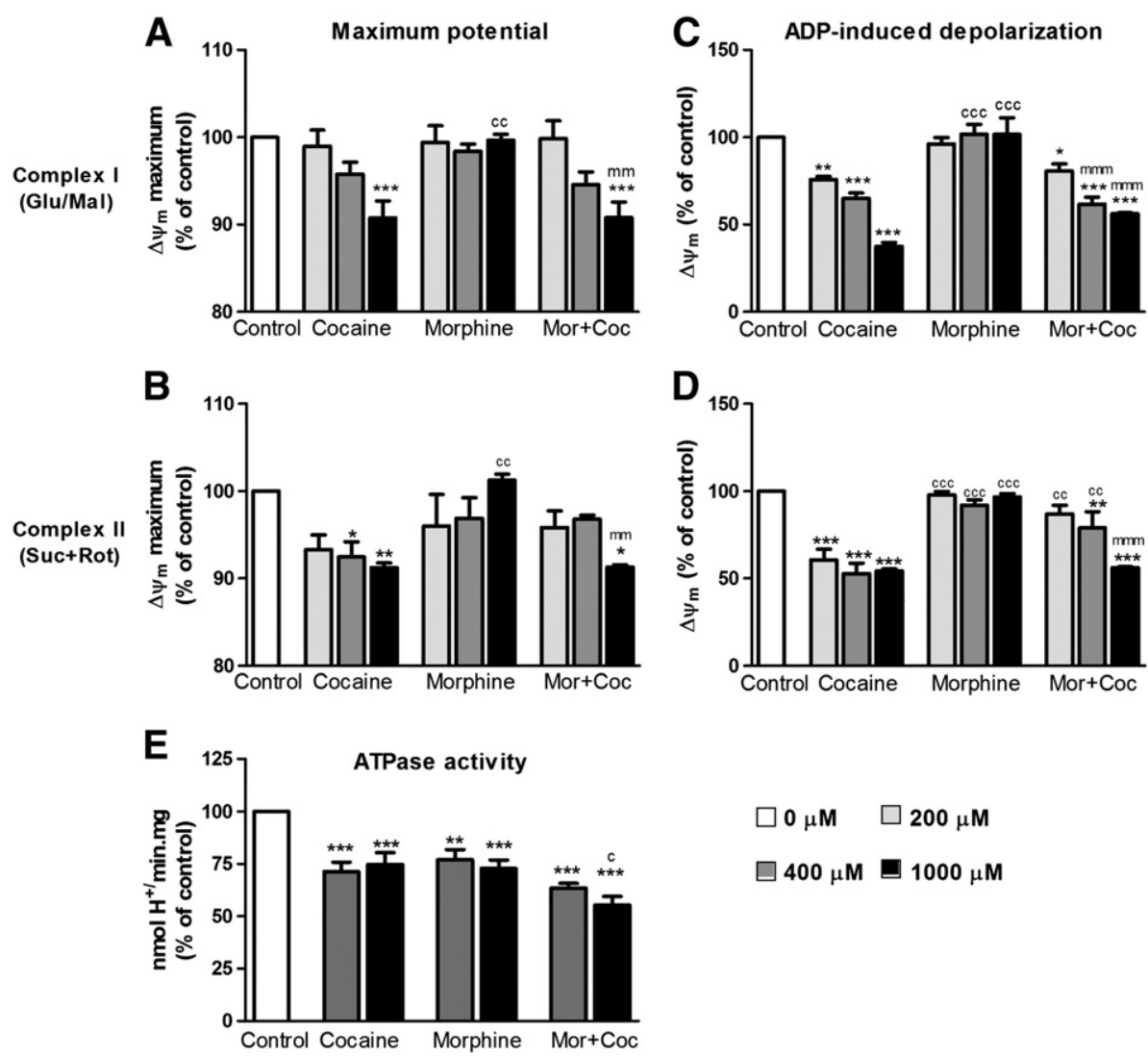

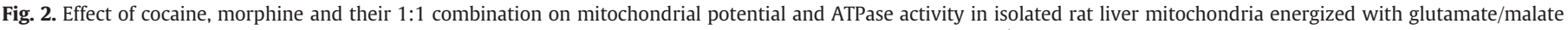

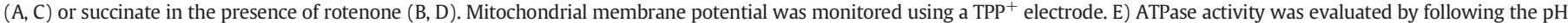

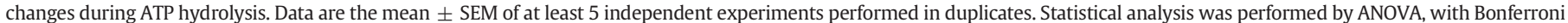

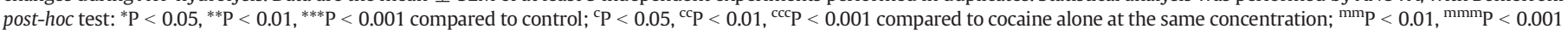
compared to morphine alone at the same concentration.

\section{Discussion}

Since both cocaine (Van Thiel and Perper, 1992) and morphine (Bekheet, 2010) have been shown to induce hepatotoxicity, the main objective of the present study was to assess whether the combination Mor $+\operatorname{Coc}(1: 1)$ altered the toxicity manifested by these drugs in the mitochondria isolated from rat liver, which is highly relevant because heroin (which is converted into morphine upon consumption) and cocaine are frequently co-consumed in a combination known as speedball (Leri et al., 2003). Given that adolescents represent a major concern regarding cocaine (Wong et al., 2013) and heroin (Hopfer et al., 2002) abuse, this work was performed with liver mitochondria isolated from adolescent rats.

Some concerns may be raised regarding the drug concentrations used in this study (from 0.2 to $1 \mathrm{mM}$ ). However, cocaine plasma concentrations in human drug abusers may range between $0.3 \mu \mathrm{M}$ and $1 \mathrm{mM}$ (Heard et al., 2008; Yuan and Acosta, 2000) and are therefore comparable to the concentrations used in this study, which are also in the range of concentrations previously used by other investigators (Boess et al., 2000; Yuan and Acosta, 2000). In contrast, the concentrations of morphine used in our experiments are significantly higher than the peak plasma levels found in fatalities implicating morphine abuse, which range from 0.20 to $2.3 \mathrm{mg} / \mathrm{l}$ (Baselt, 2000), corresponding to $0.35-9.8 \mu \mathrm{M}$. Importantly, both drugs accumulate in intracellular compartments, and, therefore, blood levels grossly underestimate intracellular concentrations. The concentrations of morphine used in this study were chosen to maintain the $1: 1$ proportion between cocaine and morphine, at which cocaine:morphine adducts are formed (Garrido et al., 2007). Although we used a high concentration of morphine, it seems to be well tolerated by the liver mitochondria, since only slight effects have been observed.

Multiple investigations suggest that cocaine affects mitochondrial function. Previous studies from our laboratory suggested that a functional respiratory chain is required for cocaine's toxicity, since the rho-zero cells (without functional mitochondria) are more resistant to cocaine cytotoxicity compared to rho + cells (Cunha-Oliveira et al., 2006a). In accordance, complex I activity and the expression of its subunits were reduced (Devi and Chan, 1997; Dietrich et al., 2004;Yuan and Acosta, 2000) and mitochondrial gene expression was found to be down-regulated (Dietrich et al., 2004), upon exposure to cocaine. Furthermore, microarray data suggested that mitochondrial functions and energy metabolism are affected in brains of human cocaine abusers (Lehrmann et al., 2003). Liver mitochondrial bioenergetics was found to be affected by cocaine, since in vivo cocaine administration decreased state 3 respiration and RCR of hepatic mitochondria from rat (Devi and Chan, 1997) and mice (Leon-Velarde et al., 1992), and also decreased the activity of complexes I, II/III, and IV (Devi and Chan, 1997). Importantly, cocaine metabolism may affect its toxicity when administered in vivo, since the cocaine metabolites norcocaine and $\mathrm{N}-\mathrm{OH}$-norcocaine are more effective affecting state 3 , state 4 , RCR, and ADP/O in mitochondria isolated from rat liver, compared to cocaine itself (Boess et al., 2000). Interference of cocaine with mitochondrial function may possibly be explained by the formation of cocaine-protein adducts, which occurs primarily with proteins located in mitochondrial and microsomal fractions, such as HSP-60 and transferrin (Ndikum-Moffor and Roberts, 2003).

Our present results support the idea that cocaine affects the respiratory chain, since cocaine interfered with respiration at states 2,4 , 
A

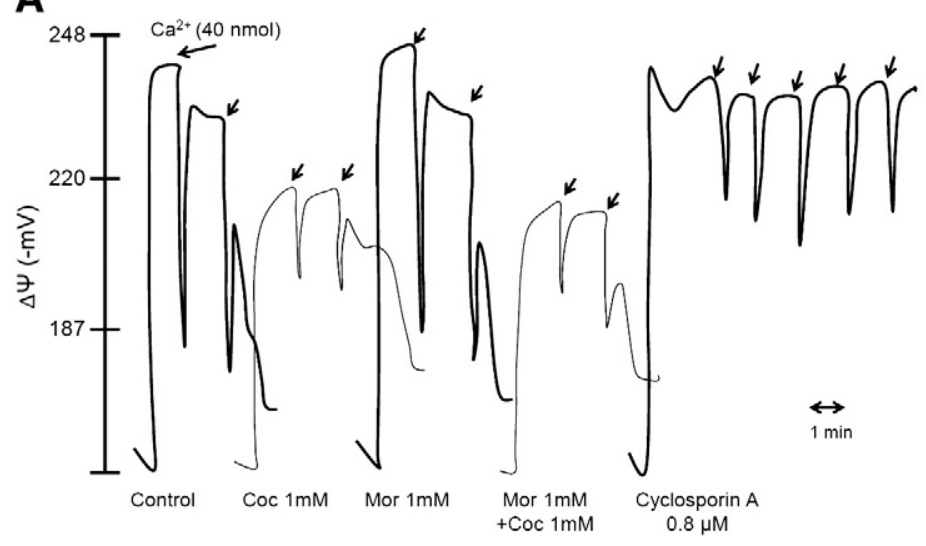

B

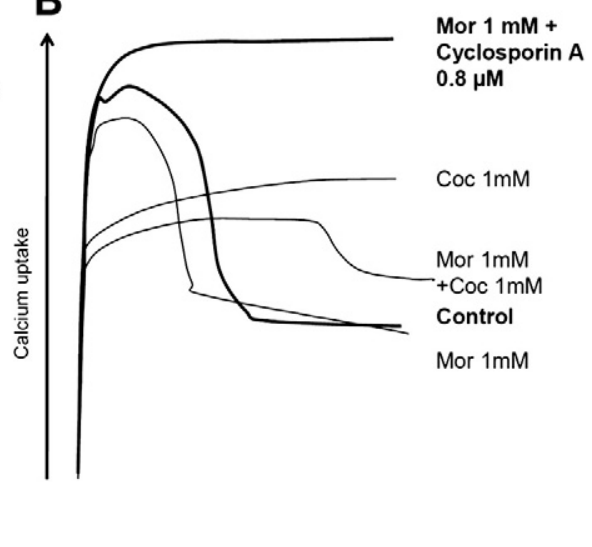

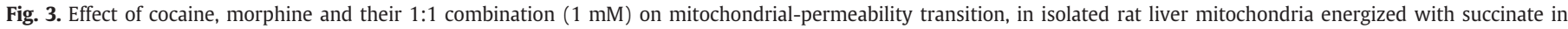

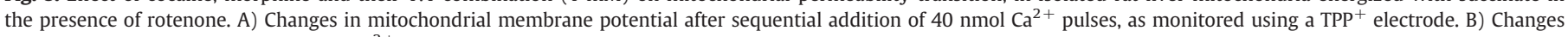
in calcium uptake as measured using a $\mathrm{Ca}^{2+}$ electrode. Data are representative of at least 5 independent experiments performed in duplicates.

oligomycin and FCCP. The increase in states 2 and 4 respiration in the mitochondria exposed to cocaine suggests an increase in passive transport of $\mathrm{H}^{+}$into the mitochondria, which is supported by the observed increase in the state oligomycin. This passive transport may be due to a bilateral damage in phospholipids or to the opening of the MPT pore. However, in our conditions, cocaine did not induce the opening of the MPT pore, suggesting that $\mathrm{H}^{+}$may enter the mitochondria by passive permeability. Under these experimental conditions, the $\Delta \Psi$ decreased significantly due to inhibition of complex I, since state FCCP in the presence of glutamate/malate is significantly reduced as opposed to state FCCP in the presence of succinate. The induced decrease of $\Delta \Psi$ by cocaine in the mitochondria energized with succinate may be explained by its direct dissipative charge effect, since at physiological pH cocaine is positively charged (Sulzer and Rayport, 1990) and may accumulate inside the organelle, which is known as the weak base effect. Cocaine has also been shown to affect mitochondrial potential in rat cortical neurons (Cunha-Oliveira et al., 2006a, 2010) and cardiomyocytes (Xiao et al., 2000). The depolarization induced by ADP was also significantly decreased in the mitochondria incubated with cocaine, which may result from a direct effect of the drug in the ATP synthase/ATPase, since the activity of this enzyme (specifically the $F_{1}$ subunit) decreased in the presence of cocaine.
Morphine is clinically used for the treatment of severe pain (Bekheet, 2010), and is also the active metabolite of heroin, mediating many of its effects (Cunha-Oliveira et al., 2008). Furthermore, cocaine and morphine were shown to interact in mixtures of cocaine and heroin used by speedball abusers (Garrido et al., 2007). Morphine and heroin were shown to affect mitochondrial function. Morphine (0.01-0.1 mM) was previously shown to decrease state 4 , and to increase state $3, \mathrm{RCR}$ and $\mathrm{ADP} / \mathrm{O}$ in the mitochondria isolated from rat brain (Feng et al., 2008). Exposure to heroin was previously found to decrease $\Delta \Psi$ and induce cell death through mitochondria-dependent apoptotic pathway in rat cortical neurons (Cunha-Oliveira et al., 2007). In the present study, morphine $(0.2-1 \mathrm{mM})$ did not affect most of the respiratory parameters, except for state 2 . Morphine also presented an inhibitory effect in ATPase activity, in accordance with some in vivo studies which showed that morphine also decreases the activity of $\mathrm{Na}^{+}-\mathrm{K}^{+}$ATPase and total ATPase in rat brain tissue (Guzman et al., 2006).

Oxidative stress seems to be involved in cocaine's mitochondrial effects, as demonstrated by the fact that cocaine-induced cardiac mitochondrial dysfunction may be prevented by the mitochondrial-targeted antioxidant MitoQ (Vergeade et al., 2010). Interestingly, adaptation to oxidative stress induced by cocaine may explain the partial resistance against $\mathrm{H}_{2} \mathrm{O}_{2}$ toxicity observed in $\mathrm{PC} 12$ cells chronically exposed to

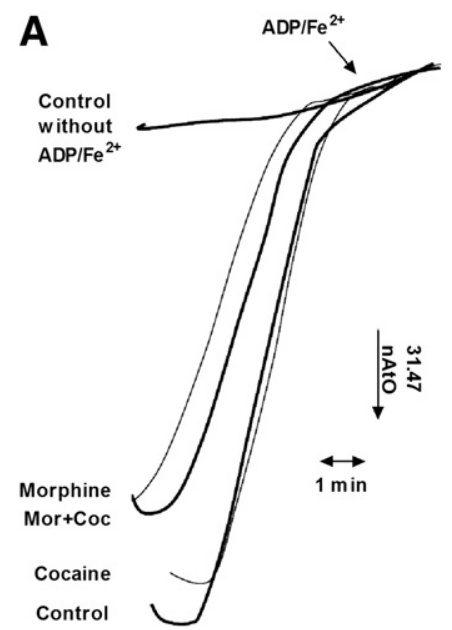

B

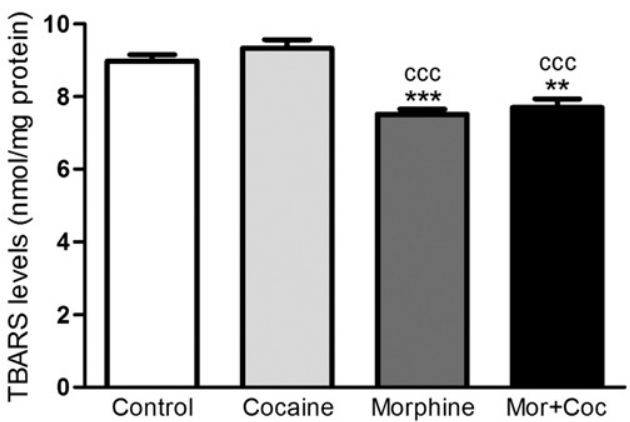

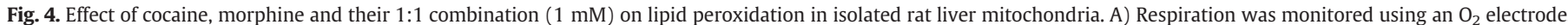

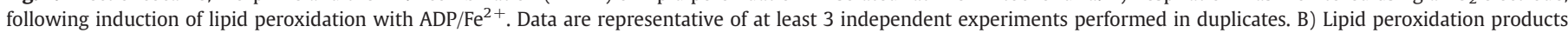

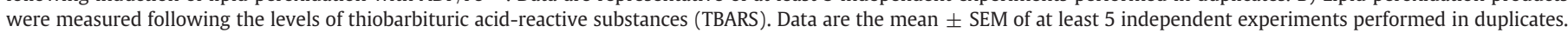
Statistical analysis was performed by ANOVA, with Bonferroni post-hoc test: ${ }^{* *} \mathrm{P}<0.01,{ }^{* * *} \mathrm{P}<0.001$ compared to control; ${ }^{\text {ccc }} \mathrm{P}<0.001$ compared to cocaine alone. 

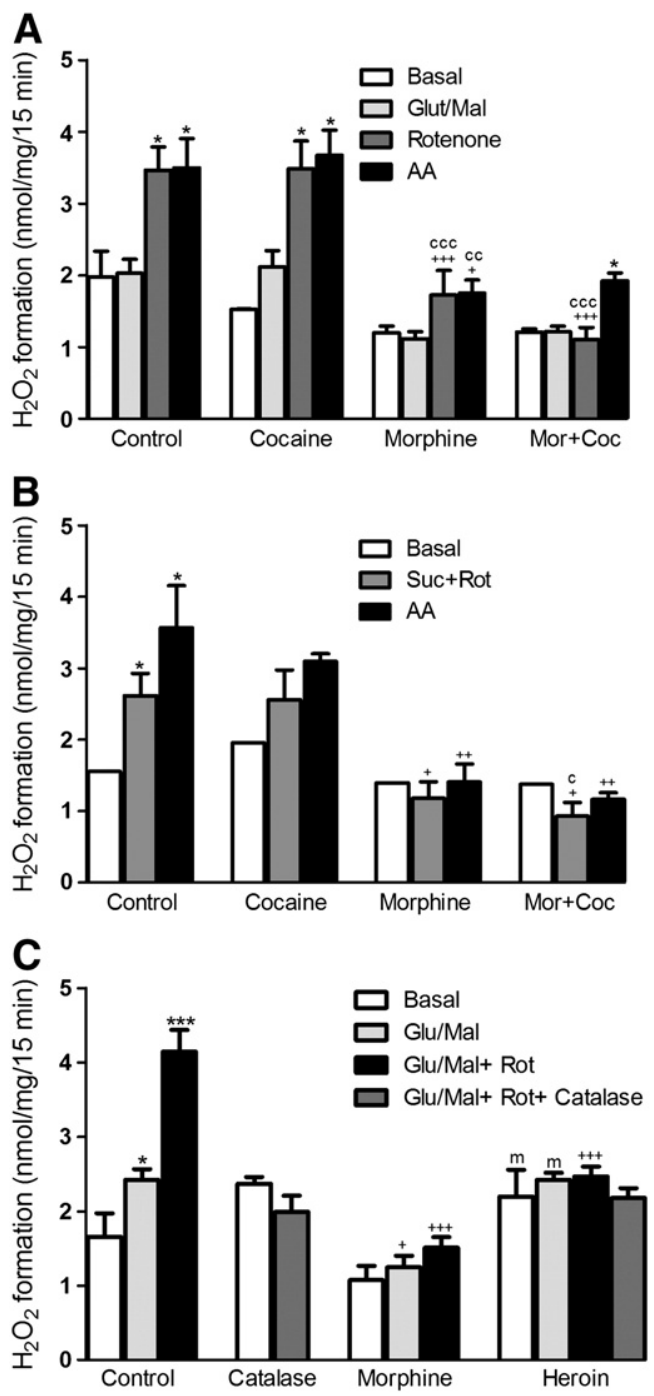

Fig. 5. Effect of cocaine, morphine and their $1: 1$ combination ( $1 \mathrm{mM})$ on $\mathrm{H}_{2} \mathrm{O}_{2}$ formation in isolated rat liver mitochondria energized with (A) glutamate/malate (Glut/Mal) or (B) succinate (Suc) in the presence of rotenone (Rot). The effect of morphine on $\mathrm{H}_{2} \mathrm{O}_{2}$ formation in glutamate/malate energized mitochondria was compared with the effect of heroin (C). Data are the mean \pm SEM of at least 3 independent experiments performed in duplicates. Statistical analysis was performed by ANOVA, with Bonferroni post-hoc test: ${ }^{*} \mathrm{P}<0.05,{ }^{* *} \mathrm{P}<0.01,{ }^{* * *} \mathrm{P}<0.001$ compared to respective basal condition; ${ }^{+} \mathrm{P}<0.05$, ${ }^{++} \mathrm{P}<0.01,{ }^{+++} \mathrm{P}<0.001$ compared to respective control condition ${ }^{\mathrm{C}} \mathrm{P}<0.05$, ${ }^{\mathrm{ccc}} \mathrm{P}<0.01$, ${ }^{\text {ccc }} \mathrm{P}<0.001$ compared to cocaine alone. ${ }^{\mathrm{m}} \mathrm{P}<0.05$ compared to morphine alone.

cocaine (Cunha-Oliveira et al., 2006b), suggesting the involvement of oxidative stress in the chronic effects of cocaine. In accordance, cocaine-induced adaptations in cellular redox balance seem to contribute to enduring behavioral plasticity (Uys et al., 2011), and, thus, cocaine-induced oxidative stress seems to play an important role in the addictive properties of this drug (Cunha-Oliveira et al., 2008). Previous studies showed that cocaine can increase lipid peroxidation in the brain of rats exposed in utero to this drug (Bashkatova et al., 2006). Cocaine also increases the levels of $\mathrm{H}_{2} \mathrm{O}_{2}$ in dopaminergic structures of rat brain (Dietrich et al., 2005) and the levels of reactive oxygen species in rat heart mitochondria (Vergeade et al., 2010). Here, we showed that cocaine did not affect lipid peroxidation or the formation of $\mathrm{H}_{2} \mathrm{O}_{2}$ in the mitochondria isolated from rat liver. Oxygen consumption and production of TBARS upon $\mathrm{ADP} / \mathrm{Fe}^{2+}$ stimulation, and the formation of $\mathrm{H}_{2} \mathrm{O}_{2}$ were similar in the mitochondria incubated with cocaine and in the control mitochondria, suggesting that, in our conditions, cocaine effects did not involve oxidative stress mechanisms, at the mitochondrial level.
Interestingly, in this work, morphine seemed to have an antioxidant effect in isolated rat liver mitochondria, since the mitochondria incubated with this drug presented an increase in the time needed to initiate lipid peroxidation and a decrease in oxygen consumption and in TBARS formation after initiation of lipid peroxidation with the pair $\mathrm{ADP} / \mathrm{Fe}^{2+}$. The decrease in $\mathrm{H}_{2} \mathrm{O}_{2}$ production in the presence of morphine suggests that this molecule may have a "scavenger" effect (i.e., an ability to neutralize free radicals). Accordingly, morphine $(0.3-30 \mu \mathrm{M})$ was also previously shown to inhibit lipid peroxidation in the mitochondria isolated from rat brain (Feng et al., 2008). Our results are in agreement with previous studies in livers of rats chronically treated with morphine, which suggested that, in vivo, morphine may be decrease the levels of $\mathrm{H}_{2} \mathrm{O}_{2}$ by a "scavenger" effect (Miskevich et al., 2007). However, in vivo administration of morphine was also shown to increase the levels of TBARS (lipid peroxidation products) in the brain tissue (Guzman et al., 2006) and rat liver (Horid'ko et al., 2007). This discrepancy may be explained by morphine metabolism, in vivo, which may affect its antioxidant properties.

Interestingly, apomorphine, a molecule chemically similar to morphine, was shown to have a neuroprotective action in rat striatum due to its antioxidant ("scavenging" of radicals) and iron chelator properties (Grunblatt et al., 2001). Probably, in apomorphine, the benzene ring with two hydroxyl groups is responsible for its antioxidant action, since it can receive electrons, thus preventing them of reducing $\mathrm{O}_{2}$, leading to the formation of free radicals. Since morphine has a similar chemical structure, it is likely that one of the two benzene rings with the hydroxyl group is responsible for its antioxidant properties, which is supported by the fact that heroin, in which the benzene rings are not available to receive electrons, showed no antioxidant capacity.

As previously mentioned, the combined use of heroin and cocaine is very common (European Monitoring Center for Drugs and Drug Addiction, 2009), and the molecular effects of this combination are poorly understood. The combination of these drugs may modify the effects observed for each drug separately (Cunha-Oliveira et al., 2010), possibly due to adduct formation that occurs between cocaine and morphine (Garrido et al., 2007), altering their chemical properties. However, it should be noted that in the present work morphine and cocaine were incubated sequentially $(1: 1)$ from separate stock solutions to obtain the combination Mor $+\mathrm{Coc}$, possibly underlying a low extent of cocaine:morphine adduct formation, which may explain the lack of specific effects of the drug combination used in the present study.

Our present results show that rat liver mitochondria incubated with the combination Mor + Coc (1:1) presented a significantly lower $\Delta \Psi$ when compared to controls, and decreased ADP-induced depolarization, suggesting that this combination may have a direct action on the ATP synthase, which is supported by the observed decrease in mitochondrial ATPase activity. However, our results also show that, although the combination Mor + Coc (1:1) greatly decreases the $\Delta \Psi$, it does not affect the opening of the MPT pore. For the respiratory parameters, the effects of the combination Mor $+\mathrm{Coc}$ (1:1) are very similar to those caused by cocaine. On the other hand, this combination seems to have similar, but less extensive, antioxidant capacity compared to morphine administered alone.

\section{Conclusions}

Together, our results demonstrate that the effects of Mor + Coc (1:1) combination at the respiratory chain and mitochondrial potential are similar to those induced by cocaine alone. Regarding oxidative stress, the effects of the combination are similar to those induced by morphine alone. In summary, the (sequential) combination of the two drugs does not seem to modify the effects manifested by the drugs when used alone, on isolated liver mitochondria, but the antioxidant effect of morphine could minimize some deleterious actions of cocaine when the two drugs are combined. 


\section{Conflict of interest statement}

The authors declare that there is no conflict of interest.

\section{Acknowledgments}

The authors would like to thank Dr Fernanda Borges (FCUP) and Dr Jorge Garrido (ISEP), Porto, Portugal, by kindly providing a sample of heroin hydrochloride for this study. This work was supported by Grant III/34/2008 from Instituto de Investigação Interdisciplinar da Universidade de Coimbra and Grants PTDC/AGR-ALI/108326/2008 and PEst-C/SAU/LA0001/2011 funded by Fundação para a Ciência e a Tecnologia (FCT), Portugal, and cofinanced by: “COMPETE - Programa Operacional Factores de Competitividade", QREN and European Union (FEDER - Fundo Europeu de Desenvolvimento Regional). T.C.-O. was supported by the FCT postdoctoral fellowship SFRH/BPD/34711/2007 and AMS by the PhD fellowship from FCT, ref SFRH/BD/76086/2011, cofinanced by POPH - Programa Operacional Potencial Humano, QREN and European Union.

\section{References}

Barja G. The quantitative measurement of $\mathrm{H} 2 \mathrm{O} 2$ generation in isolated mitochondria. J Bioenerg Biomembr 2002;34(3):227-33.

Baselt RC. Disposition of toxic drugs \& chemicals in man. 5th ed. California: Chemical Toxicology Institute; 2000.

Bashkatova V, Meunier J, Vanin A, Maurice T. Nitric oxide and oxidative stress in the brain of rats exposed in utero to cocaine. Ann N Y Acad Sci 2006;1074:632-42.

Bekheet SH. Morphine sulphate induced histopathological and histochemical changes in the rat liver. Tissue Cell 2010;42(4):266-72.

Boess F, Ndikum-Moffor FM, Boelsterli UA, Roberts SM. Effects of cocaine and its oxidative metabolites on mitochondrial respiration and generation of reactive oxygen species. Biochem Pharmacol 2000;60(5):615-23.

Chance B, Williams GR. The respiratory chain and oxidative phosphorylation. Adv Enzymol Relat Subj Biochem 1956;17:65-134.

Cunha-Oliveira T, Rego AC, Cardoso SM, Borges F, Swerdlow RH, Macedo T, et al. Mitochondrial dysfunction and caspase activation in rat cortical neurons treated with cocaine or amphetamine. Brain Res 2006a;1089(1):44-54.

Cunha-Oliveira T, Rego AC, Morgadinho MT, Macedo T, Oliveira CR. Chronic effects of heroin and hydrogen peroxide in PC12 cells. Coimbra Med 2006b;2(1):21-9.

Cunha-Oliveira T, Rego AC, Garrido J, Borges F, Macedo T, Oliveira CR. Street heroin induces mitochondrial dysfunction and apoptosis in rat cortical neurons. J Neurochem 2007:101(2):543-54.

Cunha-Oliveira T, Rego AC, Oliveira CR. Cellular and molecular mechanisms involved in the neurotoxicity of opioid and psychostimulant drugs. Brain Res Rev 2008;58(1): $192-208$.

Cunha-Oliveira T, Rego AC, Garrido J, Borges F, Macedo T, Oliveira CR. Neurotoxicity of heroin-cocaine combinations in rat cortical neurons. Toxicology 2010;276(1): 11-7.

Custodio JB, Moreno AJ, Wallace KB. Tamoxifen inhibits induction of the mitochondrial permeability transition by $\mathrm{Ca} 2+$ and inorganic phosphate. Toxicol Appl Pharmacol 1998;152(1):10-7.

Devi BG, Chan AW. Impairment of mitochondrial respiration and electron transport chain enzymes during cocaine-induced hepatic injury. Life Sci 1997;60(11): 849-55.

Dietrich JB, Poirier R, Aunis D, Zwiller J. Cocaine downregulates the expression of the mitochondrial genome in rat brain. Ann N Y Acad Sci 2004;1025:345-50.

Dietrich JB, Mangeol A, Revel MO, Burgun C, Aunis D, Zwiller J. Acute or repeated cocaine administration generates reactive oxygen species and induces antioxidant enzyme activity in dopaminergic rat brain structures. Neuropharmacology 2005;48(7):965-74.

Estabrook R. Membranes of mitochondria and chloroplasts. New York: Van Nostrand; 1967172-212.

European Monitoring Center for Drugs and Drug Addiction. Polydrug use: patterns and responses. Luxembourg: Publications Office of the European Union; 2009. http://www. emcdda.europa.eu/attachements.cfm/att_93217_EN_EMCDDA_SI09_polydrug\%20use. pdf. http://dx.doi.org/10.2810/26783 [ISBN 978-92-9168-410-6].

European Monitoring Center for Drugs and Drug Addiction. Annual report 2012. The state of the drugs problem in Europe. Luxembourg: Publications Office of the European Union; 2012. http://www.emcdda.europa.eu/attachements.cfm/ att_190854_EN_TDAC12001ENC_.pdf. http://dx.doi.org/10.2810/64775 [ISBN 978-92-9168-538-7].

Feng Y, Lu Y, Lin X, Gao Y, Zhao Q Li W, et al. Endomorphins and morphine limit anoxiareoxygenation-induced brain mitochondrial dysfunction in the mouse. Life Sci 2008;82(13-14):752-63.

Fernandes MA, Marques RJ, Vicente JA, Santos MS, Monteiro P, Moreno AJ, et al. Sildenafi citrate concentrations not affecting oxidative phosphorylation depress $\mathrm{H} 2 \mathrm{O} 2$ generation by rat heart mitochondria. Mol Cell Biochem 2008;309(1-2):77-85.

Garrido JM, Marques MP, Silva AM, Macedo TR, Oliveira-Brett AM, Borges F. Spectroscopic and electrochemical studies of cocaine-opioid interactions. Anal Bioanal Chem 2007.

Gazzotti P, Malmstron K, Crompton M. Membrane biochemistry. In: Carafoli E, Semenza C, editors. A laboratory manual on transport and bioenergetics. New York: SpringerVerlag; 1979. p. 62-9.

Gornall AG, Bardawill CJ, David MM. Determination of serum proteins by means of the biuret reaction. J Biol Chem 1949;177(2):751-66.

Grunblatt E, Mandel S, Maor G, Youdim MBH. Effects of R- and S-apomorphine on MPTP-induced nigro-striatal dopamine neuronal loss. J Neurochem 2001;77(1): 146-56.

Guzman DC, Vazquez IE, Brizuela NO, Alvarez RG, Mejia GB, Garcia EH, et al. Assessment of oxidative damage induced by acute doses of morphine sulfate in postnatal and adult rat brain. Neurochem Res 2006;31(4):549-54.

Heard K, Palmer R, Zahniser NR. Mechanisms of acute cocaine toxicity. Open Pharmacol J 2008;2(9):70-8.

Hopfer CJ, Khuri E, Crowley TJ, Hooks S. Adolescent heroin use: a review of the descriptive and treatment literature. J Subst Abuse Treat 2002;23(3):231-7.

Horid'ko TM, Hula NM, Stohnii NA, Mehed' OF, Klimashevs'kyi VM, Shovkun SA, et al Effect of N-stearoylethanolamine on the lipid peroxidation process and lipid composition of the rat liver in acute morphine intoxication. Ukr Biokhim Zh 2007;79(5): 175-85.

Kamo N, Muratsugu M, Hongoh R, Kobatake Y. Membrane potential of mitochondria measured with an electrode sensitive to tetraphenyl phosphonium and relationship between proton electrochemical potential and phosphorylation potential in steady state. J Membr Biol 1979;49(2):105-21.

Lehrmann E, Oyler J, Vawter MP, Hyde TM, Kolachana B, Kleinman JE, et al. Transcriptiona profiling in the human prefrontal cortex: evidence for two activational states associated with cocaine abuse. Pharmacogenomics J 2003;3(1):27-40.

Leon-Velarde F, Huicho L, Monge C. Effects of cocaine on oxygen consumption and mitochondrial respiration in normoxic and hypoxic mice. Life Sci 1992;50(3):213-8

Leri F, Bruneau J, Stewart J. Understanding polydrug use: review of heroin and cocaine co-use. Addiction 2003;98(1):7-22.

Madeira VM. A rapid and ultrasensitive method to measure $\mathrm{Ca}++$ movements across biological membranes. Biochem Biophys Res Commun 1975;64(3):870-6.

Madeira VM, Antunes-Madeira MC, Carvalho AP. Activation energies of the ATPase activity of sarcoplasmic reticulum. Biochem Biophys Res Commun 1974;58(4): 897-904.

Miskevich DA, Petushok NE, Lelevich VV, Lelevich SV, Borodinskii AN. Effect of chronic morphine treatment on free radical state. Biomed Khim 2007;53(2):190-5.

Ndikum-Moffor FM, Roberts SM. Cocaine-protein targets in mouse liver. Biochem Pharmacol 2003:66(1):105-13.

Nutt D, King LA, Saulsbury W, Blakemore C. Development of a rational scale to assess the harm of drugs of potential misuse. Lancet 2007;369(9566):1047-53.

Santos MS, Santos DL, Palmeira CM, Seica R, Moreno AJ, Oliveira CR. Brain and liver mitochondria isolated from diabetic Goto-Kakizaki rats show different susceptibility to induced oxidative stress. Diabetes Metab Res Rev 2001;17(3):223-30.

Sulzer D, Rayport S. Amphetamine and other psychostimulants reduce pH gradients in midbrain dopaminergic neurons and chromaffin granules: a mechanism of action. Neuron 1990;5(6):797-808.

Uys JD, Knackstedt L, Hurt P, Tew KD, Manevich Y, Hutchens S, et al. Cocaine-induced adaptations in cellular redox balance contributes to enduring behavioral plasticity. Neuropsychopharmacology 2011;36(12):2551-60.

Van Thiel DH, Perper JA. Hepatotoxicity associated with cocaine abuse. Recent Dev Alcohol 1992;10:335-41.

Vergeade A, Mulder P, Vendeville-Dehaudt C, Estour F, Fortin D, Ventura-Clapier R, et al. Mitochondrial impairment contributes to cocaine-induced cardiac dysfunction: prevention by the targeted antioxidant MitoQ. Free Radic Biol Med 2010;49(5): 748-56.

Wong WC, Ford KA, Pagels NE, McCutcheon JE, Marinelli M. Adolescents are more vulnerable to cocaine addiction: behavioral and electrophysiological evidence. J Neurosci 2013;33(11):4913-22.

Yuan C. Acosta Jr D. Effect of cocaine on mitochondrial electron transport chain evaluated in primary cultures of neonatal rat myocardial cells and in isolated mitochondrial preparations. Drug Chem Toxicol 2000;23(2):339-48.

Xiao Y, He J, Gilbert RD, Zhang L. Cocaine induces apoptosis in fetal myocardial cells through a mitochondria-dependent pathway. J Pharmacol Exp Ther 2000;292(1): 8-14. 